El cine negro español: del spanish noir al policiaco actual

The Spanish black cinema: from the Spanish noir to the present police one

Fechas | En edición: 09/06/2020 - Publicación final: 01/01/2021

\title{
DanieI MALDONADO-CASAS
}

Universidad de Málaga. España.dmaldonadocasas@gmail.com

\section{El cine negro español: del spanish noir al policiaco actual \\ Javier MEMBA}

Madrid, 2020.

255 páginas

ISBN: 978-84-15448-46-4

\section{Resumen}

El cine negro español: del spanish noir al policiaco actual, plantea un viaje desde los antecedentes del cine negro español -años cuarenta-, hasta la actualidad. La obra, dividida en seis capítulos cuenta realmente con ocho, aunque los dos últimos se consideran anexos con funciones enciclopédicas, recorre cronológicamente la evolución del género, haciendo apuntes sobre sus largometrajes y directores más relevantes. El autor nos guía mediante comentarios y opiniones personales, que se apoyan tanto en críticas de profesionales de la época Méndez Leite o Fernández Santos-, como en declaraciones de los propios cineastas, desde Rovira Beleta a Enrique Urbizu.

\section{Palabras clave}

Cine negro; cine negro español; noir; cine policiaco; cine criminal

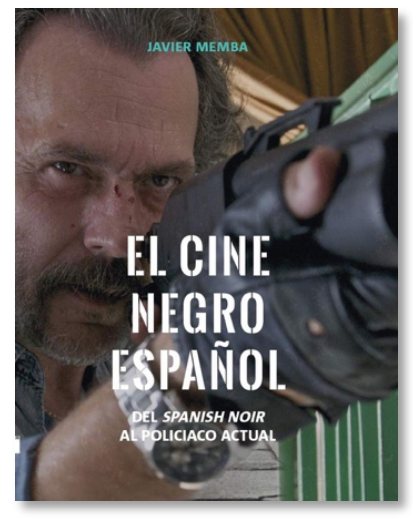

\begin{abstract}
The Spanish black cinema: from the Spanish noir to the present police one. It proposes a trip from the background of the Spanish black cinema - 1940s - to the present. The play, broken into 6 chapters - actually 8, although the last two are considered annexes with encyclopedic functions - goes chronologically through the evolution of the gender, making notes about his most relevant feature films and directors. The author guides us through comments and personal opinions, that are based in both critics from professionals of the time - Méndez Leite or Fernandez Santos - and declarations from the filmmakers themselves, from Rovira Beleta to Enrique Urbizu.
\end{abstract}

\section{Keywords}

Black cinema; spanish black cinema, police cinema, criminal cinema. 
El cine negro, a día de hoy, se sigue considerando uno de los géneros cinematográficos que más controversia causa entre teóricos y escritores, debido principalmente a dos motivos: su amplitud histórica y sus señas de identidad. Dependiendo del origen del historiador, su definición varía considerablemente. Algunos lo consideran un género producto del sistema de estudios, agotado a finales de los cincuenta; mientras que otros, defienden que no ha dejado de producirse, aunque haya mutado durante su evolución. Independientemente de las discusiones terminológicas y las dificultades para su catalogación, el noir marca un antes y un después en la cinematografía no solo americana, sino mundial. Aunque muchos espectadores lo pasen por alto, sus códigos estéticos e iconográficos no fueron adaptados solo por cineastas franceses -polar-, italianos -giallo-, o alemanes -krimi-, sino que también, aunque con un menor calado, llegaron a aterrizar en la producción nacional.

El cine negro o policiaco español, además de seguir una evolución similar a la de su precedente, también provoca controversias en cuanto a terminología y coordenadas temporales se refiere. Aunque el número de largometrajes con la impronta noir sea considerablemente inferior al de otras cinematografías, prueba la existencia de este característico género que tan ignorado ha sido dentro de nuestras fronteras. Sin pretender sentar cátedra o dar una respuesta definitiva a todos esos cabos que aún siguen sueltos, nace la propuesta de Javier Memba.

Habiendo revisado previamente obras como El cine negro español (2015) de José A. Luque Carreras, Brumas del franquismo. El auge del cine negro español (1950-1965) (2007) de Sánchez Barba o Cine negro y policíaco español de los años 50 (2000) de Elena Medina; una de las particularidades de la publicación de Memba es que, por primera vez dentro del estudio del cine negro patrio, un historiador o crítico plantea la posibilidad de no usar una única etiqueta para englobar a aquellas producciones que vieron la luz entre finales de los cuarenta y hasta nuestros días. El madrileño propone, sin entrar en debate respecto a la falta de homogeneidad a la hora hablar del género, diferenciar varios ciclos. Al primero de ellos, y adoptando el nombre que en los noventa le dio una nueva generación de cinéfilos formadas en los videoclubs, lo denomina spanish noir. Éste, se extiende desde los respetivos estrenos de Brigada Criminal (Ignacio F.lquino, 1950), y Apartado de correos 1001 (Julio Salvador, 1950), hasta A tiro limpio (Francisco Pérez-Dolz, 1963).

A raíz de las Conversaciones de Salamanca -que sirvió de punto de partida para desplazar a la antigua camada de cineastas nacionales-, y del poco apoyo que el noir recibía por parte de los espectadores, la impronta de este primer ciclo se fue diluyendo sin que fuera recogido por otro género o estética. Sin embargo, el cine policiaco español continuó gracias a figuras como la de Antonio Isasi-Isasmendi (que dispone de un capítulo independiente dentro del libro) que cultivó lo que Memba denomina thriller cosmopolita. El término engloba a tres largometrajes en cuestión: Estambul 65 (1965), Las Vegas 500 millones (1968) y Un verano para matar (1972); que comparten dos características comunes: son coproducciones y sus tramas hacen desplazar a sus protagonistas hasta escenarios internacionales que levantaban el interés del público. Los filmes del cineasta madrileño rechazan la pesadumbre y el dramatismo del antiguo spanish noir para adentrarse en un terreno más cercano a la intriga con aires de comedia y positividad. A pesar de sus diferencias, sirven de nexo entre los relatos criminales de las décadas anteriores y el segundo ciclo del género, que, en esta ocasión, si es denominado: cine negro o neonoir. Memba sostiene que a partir del estreno de El Crack (José Luis Garci, 1981), se inaugura este nuevo periodo en el que tienen cavidad tanto filmes que mitifican el cine negro clásico del Hollywood-Beltenebros (Pilar Miró, 1991)-, como otros -catalogados como thrillers-, de aires autóctonos: desde Fanny pelopaja (Vicente Aranda, 1984) y Todo por la pasta (Enrique Urbizu, 1991), hasta las aportaciones más actuales de Rodrigo Sorogoyen (Que Dios nos perdone, 2016; y El reino, 2018), Raúl Arévalo (Tarde para la ira, 2016) o Kike Maílo (Toro, 2016).

La propuesta de Memba presenta una estructura narrativa que se mantiene idéntica en cada capítulo, y que se basa en destacar obras y realizadores emblemáticos de cada etapa del noir español. En la introducción, deja claro que su objetivo es iniciar un viaje desde los precedentes del género -allá por los cuarenta-, hasta la actualidad. El segundo capítulo, dedicado en exclusividad al spanish noir, parte de la inauguración del ciclo hasta su agotamiento. Sin pretensiones enciclopédicas -ya que apenas menciona aquellos largometrajes que no guardan el aire crítico y dramático del cine negro-, recorre de manera individualizada y cronológica la carrera de los cineastas más sobresalientes del periodo -Nieves Conde, Rovira Beleta, Iquino o Julio Coll, por mencionar algunos-, comentando aspectos característicos de sus obras más significativas, sin aspirar a ser un análisis fílmico en profundidad. De esta manera, el autor confiere un aire más narrativo a sus líneas, facilitando a los lectores el seguimiento de sus explicaciones.

El tercer capítulo, centrado en la figura de Isasi-Isasmendi, mantiene una configuración similar a la anterior. El cuarto, ahonda en el giallo español, un subgénero del relato policiaco que, influenciado por el cine italiano, se convierte en uno de los más representativos de la pantalla de los años setenta, gracias a figuras como la de Eloy de la Iglesia. Reparando, sin entretenerse demasiado, en las propuestas del realizador 
vasco, Memba liga con el siguiente capítulo (el quinto), que orbita entorno al ya conocido cine quinqui. Este subgénero, que el autor considera falto de voluntad de estilo y excesivo naturalismo -rasgos que lo llevaron a su desaparición-, dio protagonismo a seres marginales desde mediados de los setenta y hasta finales de los ochenta, gracias a dos de sus máximos exponentes: el cineasta antes referido y José Antonio de la Loma.

Por último (capítulo seis), Memba nos invita a ahondar en el resurgimiento de un nuevo cine negro que, en sus inicios, trató de imitar el estilo tradicional del clasicismo del Hollywood de los años cuarenta, para, con la entrada de nuevos cineastas -Daniel Monzón, Alberto Rodríguez, Enrique Urbizu o Rodrigo Sorogoyen-, alejarse de la nostalgia de ese cine ya desaparecido, sentando las bases de un noir más patrio, que evade las copias y que adopta una idiosincrasia propia y autóctona. Este proceso de cambios y mutaciones, acontecido entre los ochenta y los noventa, le permitió al género llegar hasta su segunda edad dorada, de la que aún disfruta.

Leer El cine negro español. Del spanish noir al policiaco actual nos permite tener una acertada visión global de lo que fue y sigue siendo el género dentro de nuestra cinematografía, dándonos a conocer la amplia diversidad de cineastas y obras que, con mayor o menor gloria, tuvieron algo que decir durante sus más de siete décadas de existencia. Aunque carezca de un epílogo que hubiese cerrado la obra con una conclusión reflexiva, es un libro que llega en un momento perfecto para demostrar que, todos los thrillers españoles que de tanto éxito gozan actualmente, beben de una tradición que a la vez que extensa, es desconocida por la mayoría de los espectadores. Sin duda, e independientemente del término con el que nos refiramos a él, el noir nacional existió y sigue estando muy vigente.

\section{Referencias bibliográficas}

Medina, E. (2000). Cine negro y policíaco español de los años 50. Barcelona: Laertes

Luque Carreras, J.A. (2015). El cine negro en español. Madrid: T\&B Editores.

Sánchez Barba, F. (2007). Brumas del franquismo. El auge del cine negro español (1950-1965). Barcelona: Universidad de Barcelona. Colección Libros Film-Historia. 